\title{
Restoration of membrane TNF-like activity by cell surface targeting and matrix metalloproteinase- mediated processing of a TNF prodrug
}

\author{
J Gerspach ${ }^{1,4}$, D Müller ${ }^{1,4}$, S Münkel ${ }^{1}$, O Selchow ${ }^{1}$, J Nemeth ${ }^{1}$, \\ M Noack $^{1}$, H Petrul ${ }^{2}$, A Menrad ${ }^{2}$, H Wajant ${ }^{3}$ and K Pfizenmaier ${ }^{*, 1}$ \\ 1 Institute of Cell Biology and Immunology, University of Stuttgart, Germany \\ 2 Anti-angiogenesis Research, CRBA Oncology, Schering Laboratories, Berlin, \\ Germany \\ ${ }^{3}$ Department of Internal Molecular Medicine, Medical Polyclinic, University of \\ Würzburg, Germany \\ ${ }^{4}$ These two authors contributed equally to this work \\ * Corresponding author: K Pfizenmaier, Institute of Cell Biology and \\ Immunology, University of Stuttgart, Allmandring 31, 70569 Stuttgart, \\ Germany. Tel: + 49711685 6988; Fax: + 497116857484 \\ E-mail: klaus.pfizenmaier@izi.uni-stuttgart.de
}

Received 24.3.05; revised 13.6.05; accepted 14.6.05; published online 29.7.05 Edited by J Tschopp

\begin{abstract}
Tumor necrosis factor (TNF) prodrugs are fusion proteins comprised of an $\mathrm{N}$-terminal single-chain antibody variable fragment (scFv) targeting a TNF effector and a C-terminal TNF receptor (TNFR)1-derived inhibitor module. Introduction of matrix metalloproteinase (MMP)-2 recognition motifs between TNF and the TNFR1 fragment allowed activation by recombinant MMP-2 and MMP-expressing HT1080 cells. Processing by endogeneous MMPs required specific membrane binding of the TNF prodrug via the targeting ScFv, ensuring strictly antigen-dependent activation. Interestingly, TNF bioactivity of the processed prodrug was $\sim 1000$-fold higher upon scFv-mediated targeting, and signaled juxtatropic cell death also to antigen-negative cells. Microscopical analyses of TNFR2 clustering and TNF receptor-associated factor 2 recruitment at contact sites to adjacent cells revealed the formation of stable TNFR complexes by target-bound, processed prodrug, resembling the increased signal capacity of natural, membrane-expressed TNF. MMP-2-sensitive TNF prodrugs represent novel cytokine-based reagents for targeted cancer therapy, which should be exploitable for MMP-overexpressing tumors.

Cell Death and Differentiation (2006) 13, 273-284.

doi:10.1038/sj.cdd.4401735; published online 29 July 2005
\end{abstract}

Keywords: targeted TNF activation; prodrug processing; matrix metalloproteinase; signal complex formation; cell death

Abbreviations: Ab, antibody; CFP, cyan fluorescent protein; ED-B, extra domain B; FAP, fibroblast activation protein; MMP, matrix metalloproteinase; MT1-MMP, membrane-type matrix metalloproteinase 1; TACE, TNF alpha-converting enzyme; TIMP-2, tissue inhibitor of metalloproteinase 2; TNF, tumor necrosis factor; TNFR, TNF receptor; TRAF2, TNF receptor- associated factor 2; scFv, single-chain antibody variable fragment; scFv 36, FAP-specific scFv; scFv L19, ED-B fibronectinspecific scFv; YFP, yellow fluorescent protein

\section{Introduction}

Until today, the clinical use of tumor necrosis factor's (TNF's) potent antitumor activity is restricted to the regional treatment strategies of isolated limb or liver perfusion, where TNF is successfully applied in combination with melphalan in unresectable extremity sarcoma, in transit melanoma and advanced refractory cancers confined to the liver. ${ }^{1}$ Conventional systemic administration of TNF has been impeded so far because of its severe systemic toxicity. To overcome this problem, several attempts are presently undertaken to achieve a useful therapeutic window for systemic TNF application (for reviews, see Mueller ${ }^{2}$ and Corti $^{3}$ ).

A particular promising strategy aims at specific enrichment of TNF in the tumor area by targeting TNF via antibody (Ab) or ligand conjugation to tumor-associated antigens. Several recent examples where TNF has been fused to recombinant antibodies $^{4,5}$ or short peptides ${ }^{6,7}$ illustrate the potential of this approach. In mouse tumor models, these TNF derivatives have been shown to possess superior antitumor activity compared to recombinant soluble TNF, and this effect was more pronounced in combination with chemotherapeutics. ${ }^{4,8,9}$ Other strategies to increase the therapeutic activity of TNF by decreasing its systemic toxicity include mutagenesis, ${ }^{10,11}$ covalent modification with polyethylene-glycol or bioconjugation to polyvinyl-pyrrolidone. ${ }^{12-14}$ Despite this progress, none of these approaches has entered clinical evaluation yet. It is therefore uncertain whether improvements revealed in preclinical models are sufficient to achieve a level of safety amenable for clinical application. Accordingly, the development of safer and more efficient variants is still a major goal in TNF-based cancer therapy.

Previously, we demonstrated that, in principle, it is possible to construct a TNF prodrug displaying, like chemical prodrugs, ${ }^{15-17}$ features of targeted activity. By fusion of a TNF receptor (TNFR) fragment via a protease-sensitive linker to the $\mathrm{C}$-terminus of a single-chain $\mathrm{Ab}$ variable fragment (scFv)TNF fusion protein, an inactive human TNF prodrug was generated. This TNF prodrug was a homotrimeric protein that could be activated by limited tryptic digest. ${ }^{18}$ The aim of this work here was to construct TNF prodrugs (i) targeted to abundant and frequent markers of solid tumors, (ii) comprising linkers specified for cleavage by tumor-pathophysiologyrelevant proteases and (iii) study their mechanisms of activation and signaling towards targeted and nontargeted tumor cells. The targeting devices are single-chain fragments (scFv) specific for two abundant tumor stroma markers, fibroblast activation protein (FAP), highly expressed in 
reactive stromal fibroblasts, ${ }^{19}$ and fibronectin extra domain $B$ (ED-B), respectively, found associated with the neovasculature of solid tumors at high levels. ${ }^{20,21}$ Promising enzymes for prodrug activation are matrix metalloproteinases (MMPs), in particular MMP-2 (gelatinase A). MMPs are reported to be expressed largely in the stromal fibroblasts of many types of solid tumors, such as melanoma, breast and colon cancer, and are considered to be involved in tumor progression, angiogenesis and metastasis. ${ }^{22-25}$ To generate an MMP2-sensitive TNF prodrug, we have created two linkers with different, repeated sequence motifs optimized for MMP-2 cleavage 26,27 for insertion between TNF and the TNFR fragment. The in vitro models show the functionality of TNF prodrugs, which are targeted to and processed by antigen positive, MMP-2-expressing cells, thereby unmasking a high signal capacity of the membrane-bound, activated construct.

\section{Results and Discussion}

\section{Production of recombinant TNF prodrugs}

The molecules constructed here (Figure 1a) are comprised of mutant form of mouse TNF in which the first nine amino acids of its soluble form had been deleted and a mutation introduced at position $11(\Delta 1-9, \mathrm{~K} 11 \mathrm{E})$ in order to avoid potential cleavage of the prodrug by its natural processing enzyme TNF alpha-converting enzyme (TACE). Species crossreactive scFvs were used as targeting modules, separated from TNF by either a serine-glycine linker or a tenascin linker, which allows formation of intermolecular disulfide bridges, thereby potentially enhancing the homotrimeric assembly and stability of the prodrug at dilute concentrations. ${ }^{18}$ The tenascin linker variant was extended by a stretch of 23 amino acids of the murine TNF proform as an additional spacer. No apparent differences in expression and in vitro stability were observed for constructs differing in the linker between ScFv and TNF (data not shown). The ligand-binding domain of human TNFR1, which binds murine and human TNF with equal affinity, was used as the TNF-inhibiting module. TNFR1 was connected to the scFv-TNF fusion protein via two distinct linkers (PL1 and PL2), each comprising three consecutive repeats of the motive GPLG-VRGK ${ }^{27}$ and HPVG-LLAR, ${ }^{26}$ respectively, reported to be preferentially cleaved by MMP-2. An MMP-2-insensitive control construct ( $\alpha$ FAP-S-PLO), in which the MMP-2-sensitive linker was replaced by a serine-glycine linker of equal length, was also generated (Figure 1a).

Based on our previous results with a human TNF prodrug, ${ }^{18}$ we expected that the murine TNF prodrug fusion proteins generated here should assemble into homotrimeric molecules of $\sim 200 \mathrm{kDa}$ by virtue of TNF's intrinsic property to form trimers. Under reducing conditions, Western blot analysis showed one band of $\sim 65 \mathrm{kDa}$ for each of the four fusion proteins (Figure 1b), corresponding to the calculated molecular weight of a prodrug monomer of $63 \mathrm{kDa}$ for $\alpha$ EDB-S-PL2, $66 \mathrm{kDa}$ for $\alpha$ FAP-S-PL2 and $\alpha$ FAP-S-PLO and $68 \mathrm{kDa}$ for $\alpha$ EDB-T-PL1. Under nonreducing conditions, the TNF prodrugs containing the serine-glycine linker migrated in SDS-PAGE similar as under reducing conditions, while the construct with the tenascin linker revealed the appearance of higher oligomeric complexes (data not shown), which is indicative for the formation of intermolecular disulfide bonds. Unexpectedly, in contrast to the homotrimeric organization of the previously reported human TNF prodrug, ${ }^{18}$ we noted that $\alpha$ FAP-S-PL2, which cannot form intermolecular disulfide bonds, migrates in gel filtration and native gel electrophoresis in a MW range corresponding to a hexamer (Figure 1c). A hexameric state might be driven by a specific intermolecular interaction, for example between TNF and TNFR, or the ScFv component, due to diabody formation. As the TNF prodrug $\alpha$ FAP-S-PL2 differs from the previously described prodrug ${ }^{18}$ in the peptide linkers, but not the scFv module used, the former may be responsible for allowing TNF-TNFR interactions to take place between molecules. The existence of higher MW complexes of TNF prodrugs may affect the functional activity (see below), pharmacokinetic properties and tissue distribution, which has to be considered and assessed in in vivo studies.

In some batches of purified prodrug, for example, of $\alpha \mathrm{FAP}$ S-PL2 (Figure 1b), we observed an additional band migrating at the size of the activated prodrug. Detection of this band via the $\mathrm{C}$-terminal His tag failed (data not shown), suggesting that it is a C-terminally truncated form of the prodrug protein, probably generated by endogeneous proteases of the producer cells. Nevertheless, in terms of bioactivity, this partial processing was ineffective as long as the band corresponding to the complete prodrug was dominant. Assuming that only a totally processed homotrimer is bioactive, the formation of heterotrimers comprised of processed and full-length prodrug forms would not lead to restoration of TNF activity.

\section{MMP-2-mediated cleavage and antigen-specific binding of the TNF prodrug}

Western blot analyses of $\alpha$ EDB-T-PL1, $\alpha$ EDB-S-PL2 and $\alpha$ FAP-S-PL2 revealed processing upon in vitro treatment with recombinant, active MMP-2 by shift in the apparent MW corresponding to the size of native prodrugs to that of $a$ scFV-TNF fusion protein ( $\sim 45 \mathrm{kDa}$, Figure $1 \mathrm{~b})$. By contrast, treatment of $\alpha$ FAP-S-PLO with recombinant MMP-2 did not result in detectable processing, as evident from a quantitatively unchanged band migrating at the size of the untreated molecule. Thus, MMP-2 cleavage of the prodrug was dependent on a specific MMP-2 cleavage motif within the linker region between the TNF and TNFR1 domains.

Specific target binding of the prodrugs was shown by ELISA for $\alpha$ EDB-S-PL2 and $\alpha$ EDB-T-PL1 (Figure 2a), and by immunofluorescence flow cytometry using FAP-expressing (Figure 2b) and parental (Figure 2c) HT1080 cells for prodrugs $\alpha$ FAP-S-PL2 and $\alpha$ FAP-S-PLO. Moreover, there was no difference in binding properties of the prodrugs before and after processing with recombinant MMP-2, as exemplified for the ED-B-specific prodrug $\alpha$ EDB-T-PL1 (Figure 2d). These data indicate that neither the TNFR fragment nor MMP-2 processing affected the antigen-binding capacity of the prodrug. 
a

leader scFv linker 1 muTNF linker 2 TNF-R1 tags

$\alpha$ EDB-T-PL 1

N-

$\alpha$ ED-B

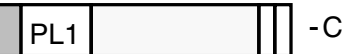

$\alpha$ EDB-S-PL2

N-

\begin{tabular}{|l|l|l|l|l|}
\hline$\alpha$ ED-B & $S$ & PL2 & & \\
\hline
\end{tabular}

$\alpha$ FAP-S-PL2

$\mathrm{N}-$

$\alpha$ FAP $\quad S$

PL2

N-

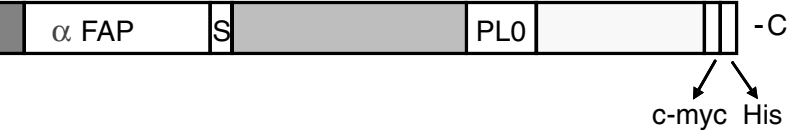

b

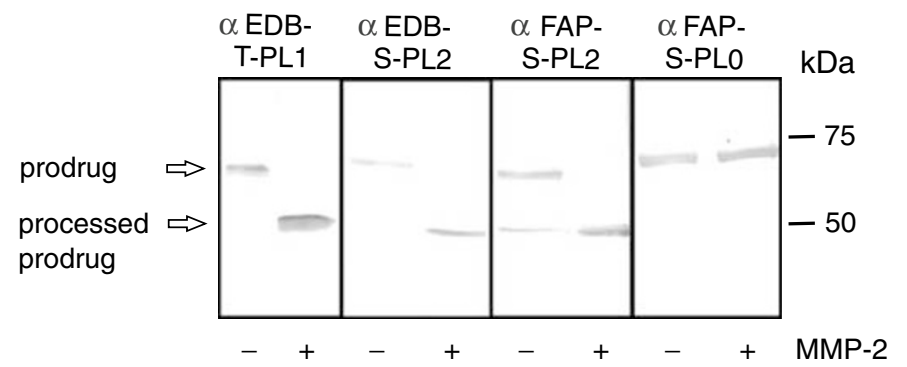

C

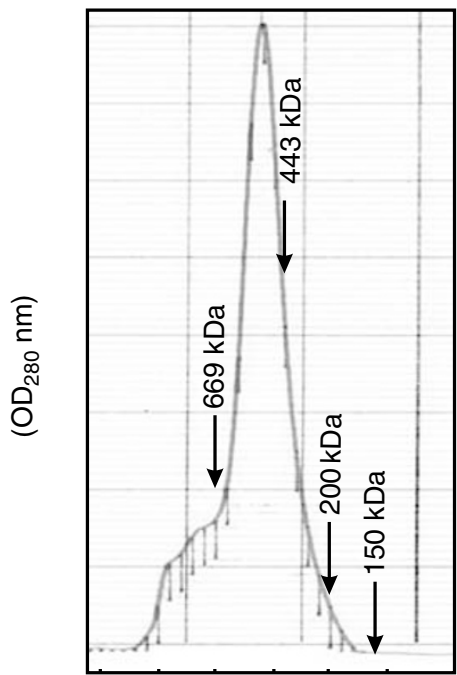

Fraction

$\begin{array}{llllll}15 & 20 & 25 & 30 & 35 & 40\end{array}$

Fraction

$\begin{array}{llllllllllllllllllll}17 & 19 & 20 & 21 & 23 & 24 & 25 & 26 & 27 & 28 & 29 & 30 & 31 & 32 & 33 & 34 & 35 & 37 & 39 & 41\end{array}$

Figure 1 Schematic overview and biochemical analyses of expressed TNF prodrug constructs. (a) Scheme of the TNF prodrug constructs $\alpha$ EDB -T-PL1, $\alpha$ EDBS-PL2, $\alpha$ FAP-S-PL2 and $\alpha$ FAP-S-PL0. $\alpha$ EDB: scFvL19; $\alpha$ FAP: scFv 36; T: tenascin domain linker; S: (serine ${ }_{4}$-glycine) 3 linker; muTNF: N-terminal deletion mutant of the soluble form of murine TNF; PL1: protease sensitive linker with three GPLG-VRGK motifs; PL2: protease sensitive linker with three HPVG-LLAR motifs; PL0: protease insensitive linker with serine-glycine motif; TNFR1: fragment of the extracellular domain of human TNFR1. (b) Western blot analysis of the TNF prodrug in its inactive and activated form. TNF prodrug $\alpha$ EDB-T-PL1, $\alpha$ EDB-S-PL2, $\alpha$ FAP-S-PL2 and $\alpha$ FAP-S-PL0 were treated for $4 \mathrm{~h}$ at $37^{\circ} \mathrm{C}$ with or without recombinant MMP-2. Proteins were separated by $12 \%$ SDS-PAGE (reducing conditions) and detected by Western blot with rabbit murine TNF-specific antibodies. (c) Gel filtration analysis of the TNF prodrug $\alpha$ FAP-S-PL2. Fractions corresponding to the observed peaks were analyzed by Western blot as described in (b) 
a

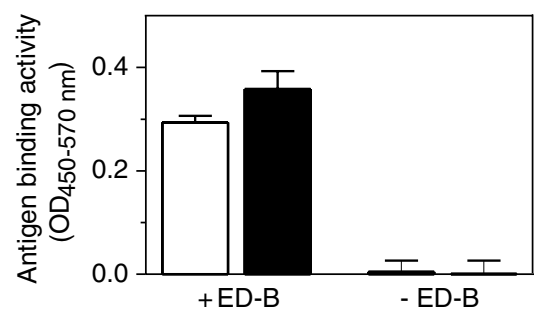

b
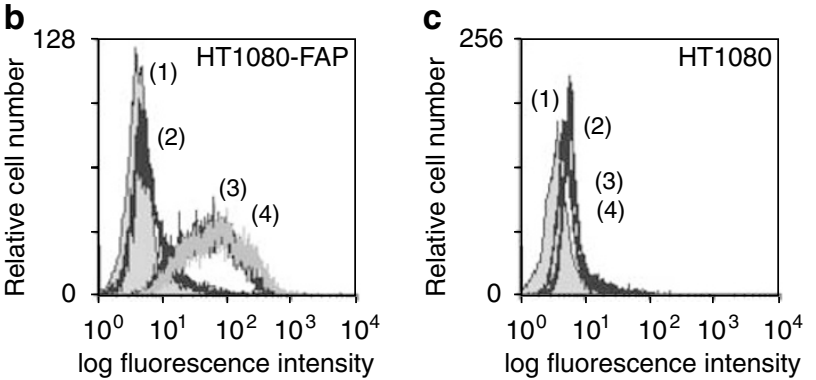

d

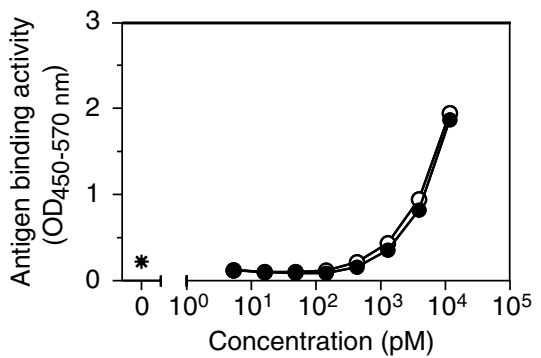

Figure 2 Antigen specificity of the TNF prodrugs. (a) Binding properties of ED-B-specific TNF prodrugs. $\alpha$ EDB-T-PL1 (open bar) and $\alpha$ EDB-S-PL2 (filled bar) were incubated on surface immobilized recombinant ED-B and detected by ELISA via protein A, which binds to the L19 scFv. (b, c) Binding properties of FAP-specific TNF prodrugs. Binding of $\alpha$ FAP-S-PL2 (3) and $\alpha$ FAP-S-PLO (4) to cell-expressed FAP was analyzed by FACS. The constructs were incubated with HT1080-FAP (b) or HT1080 WT (c) cells and detection performed via the c-myc tag by indirect immunofluorescence using FITC-labeled goat anti-mouse IgG. $\alpha$ EDB-S-PL2 (2) was taken as negative control. Untreated cells (1). (d) Processed and nonprocessed TNF prodrugs have the same antigen-binding properties. $\alpha$ EDB-T-PL1 was incubated with $\left(4 \mathrm{~h}, 37^{\circ} \mathrm{C}\right.$; $)$ or without $(O)$ recombinant MMP-2, followed by binding analysis on recombinant ED-B by ELISA. Detection was performed via Protein A. Buffer control is indicated by asterisk

\section{Cytotoxicity of the TNF prodrug activated by recombinant MMP-2}

Bioactivity of TNF prodrugs was assessed in cytotoxicity assays on Kym-1 cells, as shown for the prodrug $\alpha$ EDB-T-PL1 in Figure $3 a$ and summarized for all constructs in Table 1. As Kym- 1 cells do not express the target antigens (ED-B, FAP) recognized by the different prodrugs, this assay only reveals nontargeted TNF activity, that is, activity resembling a standard recombinant, soluble TNF molecule. All three prodrugs turned out to have a strongly reduced activity (less than $0.1 \%$ ) compared to soluble murine TNF (Figure 3a, Table 1). Treatment of the prodrugs with purified, preactivated recombinant MMP-2 led to an at least 100-fold increase in TNF bioactivity in this nontargeted TNF assay system (Table 1). Both linker sequences used proved to be suitable, which is in accordance with published data. ${ }^{26,27}$ Prodrug activation could be abrogated by preincubating MMP-2 with a
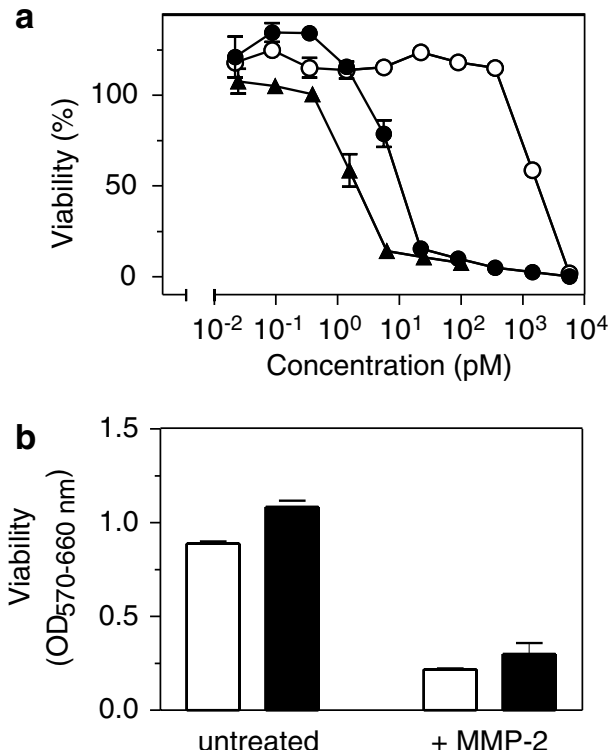

C

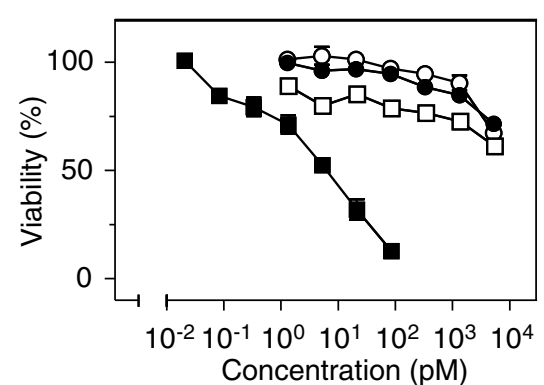

d

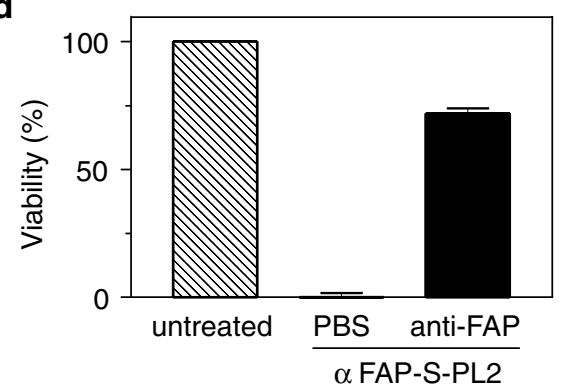

Figure 3 Prodrug activation is dependent on MMP-2 and specific binding to target antigen-expressing cells. (a) Activation of the soluble TNF prodrug by recombinant MMP-2. $\alpha$ EDB-T-PL1 was incubated with recombinant MMP-2 (-) or reaction buffer alone $(O)$ or reaction buffer alone (open circles) for $4 \mathrm{~h}$ at $37^{\circ} \mathrm{C}$. Activity of the TNF prodrug was assayed by cytotoxicity on Kym-1 cells using recombinant murine TNF $(\boldsymbol{\Lambda})$ as a positive control. (b) Activation of TNF prodrugs after binding to immobilized antigen. ED-B-specific prodrugs $\alpha$ EDBT-PL1 (open bar) and $\alpha$ EDB-S-PL2 (filled bar) were incubated for $1 \mathrm{~h}$ on plates coated with recombinant ED-B, washed and followed by $6 \mathrm{~h}$ incubation with recombinant MMP-2 $(1 \mu \mathrm{g} / \mathrm{ml})$. Plates were washed and Kym-1 cells added to assess induction of cell death during an additional $16 \mathrm{~h}$ incubation period. (c) Antigen-dependent TNF prodrug activation. HT1080-FAP $(\mathbf{Q}, \mathbf{O})$ versus HT1080 $(\square, O)$ cells were seeded and incubated the following day with the FAP-specific $\alpha$ FAP-S-PL2 (square) or ED-B specific $\alpha$ EDB-S-PL2 (circle) TNF prodrug at the indicated concentrations. (d) Binding competition assay. A FAPspecific recombinant antibody interferes with cytotoxic activity of $\alpha$ FAP-S-PL2 prodrug. HT1080-FAP cells were seeded and incubated the next day with $\alpha$ FAPS-PL2 $(17 \mathrm{ng} / \mathrm{ml})$ in the presence or absence of blocking Ab (MB36) $(13 \mu \mathrm{g} / \mathrm{ml})$ as indicated. Cell viability was determined using $\operatorname{MTT}(\mathbf{a}, \mathbf{b})$ or crystal violet staining (c, d) 
Table 1 Targeting independent cytotoxicity of activated/nonactivated TNF prodrugs

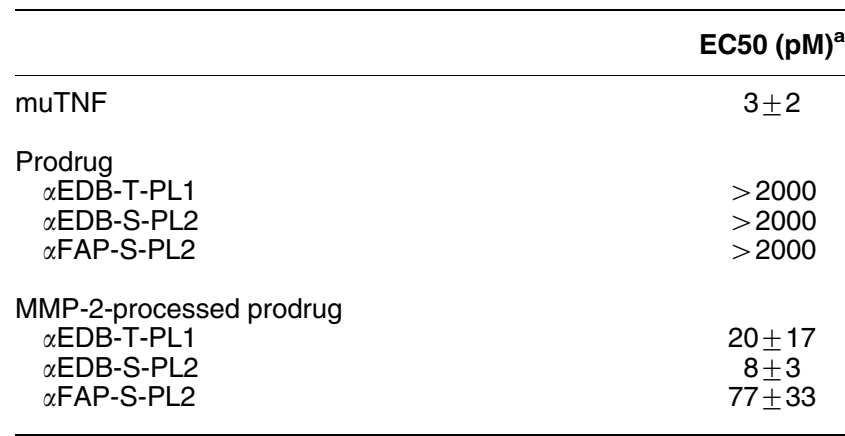

${ }^{\mathrm{a}} \mathrm{EC}_{50}$ of prodrug/muTNF was determined in cytotoxicity assays on $\mathrm{Kym}-1$ cells as described in experimental procedures. Data shown are the mean+S.D. from at least three independent bioassays and, in part, different preparations of the prodrug proteins

an MMP inhibitor (MMP-inhibitor III), demonstrating specific cleavage by MMP-2 (data not shown). Of relevance, the TNF prodrug can be processed and activated when bound to the target antigen, as shown for the two ED-B-specific prodrugs treated with MMP-2 subsequent to binding to ED-B-coated surfaces. Restoration of TNF activity was revealed by induction of cell death in Kym-1 cells added to the prodrugdecorated ED-B culture dishes after MMP-2 treatment (Figure $3 b$ ). Likewise, prodrug $\alpha$ FAP-S-PL2 can be activated when bound to target-expressing cells (see below). Comparing the nontarget-dependent bioactivities recovered after proteolytic activation of the different prodrugs, we noted in several independent experiments a higher specific activity of prodrugs containing the ED-B-specific scFv ( $\alpha$ EDB-S-PL2 and $\alpha$ EDB-T-PL1) compared to the FAP-specific prodrug $\alpha$ FAP-S-PL2 (Table 1), despite no detectable differences in processing efficacy, as revealed from Western blot analyses (Figure 1b). As $\alpha$ EDB-S-PL2 and $\alpha$ FAP-S-PL2 differ only in the $s c F v$ module, these findings suggest that, despite a similar overall structure of $\mathrm{Ab}$ fragments, the sequence differences in this module may have considerable effects on structure and function of the whole fusion protein. Interestingly, use of the FAP-specific scFv 36 together with human instead of murine TNF has resulted in a fusion protein, termed TNF selectokine, with bioactivities indistinguishable from a recombinant TNF standard. ${ }^{18}$ This TNF fusion protein contains the tenascin linker comprised of a $30 \mathrm{AA}$ coiled-coil tenascin domain, followed by a 23-AA sequence extracellular $\mathrm{N}$-terminal portion of the human TNF proform, and assembles as a homotrimeric molecule, whereas the murine TNF containing $\alpha$ FAP-S-PL2 described here has a considerably shorter, 15-AA serineglycine linker, and is apparently a hexamer (Figure 1c). As oligomerization of TNF ligands promotes bioactivity, it appears unlikely that the hexameric organization of $\alpha \mathrm{FAP}$. S-PL2 is the reason for reduced, nontargeted TNF activity of the fusion protein. Concerning the influence of the two linker sequences used between TNF and the TNFR fragment on processing and bioactivity, we could not reveal differences in the case of the EDB-specific ScFv L19-based TNF fusion proteins ( $\alpha$ EDB-S-PL2 versus $\alpha$ EDB-T-PL1, Table 1). However, during construction of other cytokine fusion proteins, we also noted a differential influence of various scFvs on the functionality of the fusion proteins with different TNF ligand family members. ${ }^{28}$ Accordingly, not only the length and sequence of the peptide linker between ScFv and effector cytokine but also the particular combination of a scFv and the TNF ligand could have an impact on overall structure and function of the fusion protein. It is our experience that the functionality of a given ScFv and TNF family ligand combination is hard to predict, and extensive linker variations and/or availability of a panel of ScFv of the same target specificity might be necessary to succeed in generation of functionally useful fusion proteins.

\section{Cell surface-targeted $\alpha$ FAP-S-PL2 induces strong cytotoxicity on cells expressing endogenous metalloproteinases}

HT1080 cells are well known to express the metalloproteinases MMP-2 and MMP-9. ${ }^{27,29}$ Moreover, in the presence of low doses of cycloheximide, HT1080 becomes highly sensitive towards apoptosis induced by all death-inducing ligands of the TNF family. ${ }^{28,30}$ Therefore, the stable FAP-expressing HT1080 transfectants enabled to study cell surface antigendependent targeting of the TNF prodrug, and to assess its conversion by endogeneous MMPs into an active, apoptosisinducing cytokine. Cytotoxicity assays on FAP-positive HT1080 cells revealed that the FAP-specific prodrug $\alpha$ FAPS-PL2 exerted a high activity without addition of exogenous MMP-2 (Figure 3c). Unexpectedly, the parental, targetnegative HT1080 cells, which are equally sensitive towards TNF-induced apoptosis $\left(\mathrm{EC}_{50}\right.$ of rec muTNF: HT1080 $0.7 \pm 0.3 \mathrm{pM}$ and HT1080-FAP $0.4 \pm 0.2 \mathrm{pM}$ ) and express comparable protein levels and activity of MMPs (data not shown), remained largely unaffected by treatment with $\alpha \mathrm{FAP}$ S-PL2 (Figure 3c). This indicates that induction of cytotoxic activity is targeting dependent, suggesting that prodrug conversion may largely occur at the cell surface. The essential role of cell surface immobilization for efficient conversion of the prodrug by endogenous MMPs was underlined with $\alpha$ EDB-S-PL2, which does not bind to HT1080 cells. Only minor cytotoxic activity at high concentrations of this prodrug was noted on both FAP-positive and -negative HT1080 cells (Figure 3c). Targeting-dependent induction of bioactivity of the prodrug was further confirmed by competition of prodrug $\alpha$ FAP-S-PL2 binding to membrane-expressed FAP with a recombinant anti-FAP-specific minibody, which inhibited cell death (Figure 3d).

Western blot analysis of the supernatant of FAP-expressing HT1080 cells incubated for $16 \mathrm{~h}$ with prodrug showed processing of $\alpha$ FAP-S-PL2 (Figure 4a), accompanied by detection of cytotoxic activity in the culture supernatant, which, however, was marginal as compared to a rec. TNF standard (Figure 4b), indicating that apoptosis induction is by and large mediated by the cell-bound, activated prodrug. Under the same conditions, $\alpha$ EDB-S-PL2 (irrelevant antigen specificity) or $\alpha$ FAP-S-PLO (not cleavable by recombinant MMP-2) remained unchanged in Western blot (Figure 4a). Of note, the specific activity of $\alpha$ FAP-S-PL2 on HT1080-FAP cells $\left(E_{50} \sim 1-2 \mathrm{pM}\right)$, that is, of the targeted, cell autonomously 

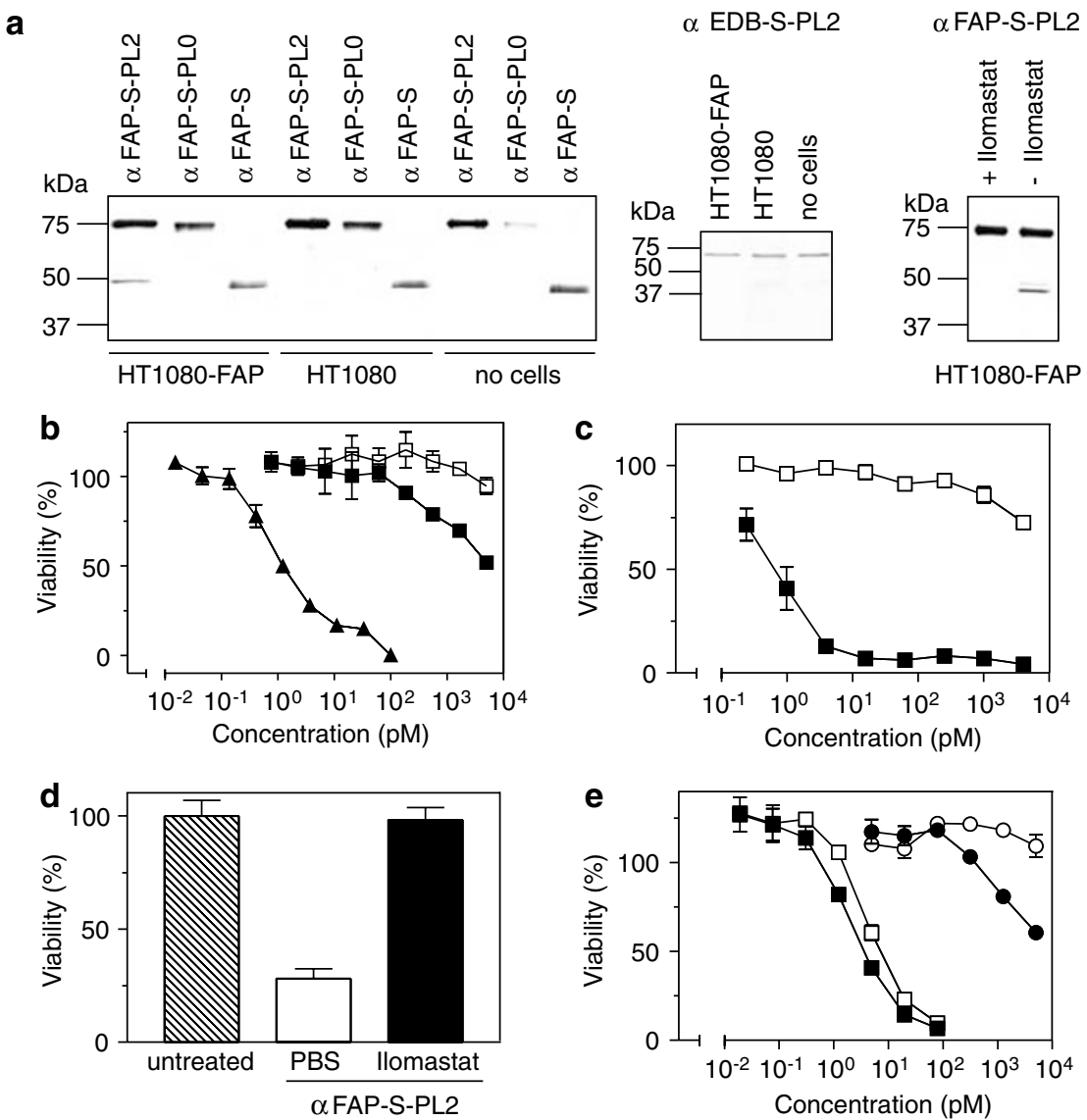

Figure 4 TNF prodrug activation by tumor cell-expressed MMPs requires targeting and the MMP-2 cleavage site. (a) Biochemical analysis of TNF prodrug processing by endogenous proteases. HT1080-FAP/HT1080 cells were seeded and incubated the following day for $16 \mathrm{~h}$ with TNF prodrug (20 nM) $\alpha$ FAP-S-PL2 (in presence or absence of the inhibitor llomastat, $25 \mu \mathrm{M}), \alpha$ EDB-S-PL2, $\alpha \mathrm{FAP}-\mathrm{S}-\mathrm{PL} 0$ or the bioactive TNF fusion protein $\alpha \mathrm{FAP}-\mathrm{S}$. Supernatants were removed and analyzed by Western blot (12\% SDS-PAGE, reducing conditions). Detection was performed via rabbit anti-murine TNF antibodies. (b) Bioactivity of soluble TNF prodrug upon cell surface processing by endogenous proteases. Cytotoxic activity present in culture supernatants of HT1080 $(\square)$ and HT1080-FAP $(\mathbf{\square})$ after 16 h incubation with $\alpha$ FAP-S-PL2 was assessed on HT1080 cells, using recombinant murine TNF $(\mathbf{\Delta})$ as a positive control. (c) TNF prodrug activation by endogeneous proteases requires the MMP-2-specific linker sequence. HT1080-FAP cells were seeded and incubated with $\alpha$ FAP-S-PL2 ( $\mathbf{\square}$ ) or $\alpha$ FAP-S-PL0 ( $\square$ ). (d) TNF prodrug activation is blocked by an MMP-inhibitor. HT1080-FAP cells were seeded and pre-incubated for $1 \mathrm{~h}$ with MMP inhibitor llomastat $(25 \mu \mathrm{M})$ before adding TNF prodrug $\alpha \mathrm{FAP}-\mathrm{S}$-PL2 (1.33 pM). (e) Cytotoxicity of $\alpha$ FAP-S-PL2 in its native (open symbol) and in vitro pre-activated (filled symbol) form on HT1080-FAP (squares) and HT1080 (circles) cells which were seeded 1 day before overnight incubation with TNF prodrug. Cell viability was determined using crystal violet staining (b-d)

processed prodrug, was close to the muTNF standard $(\sim 0.5 \mathrm{pM})$. Concerning the specificity of prodrug processing, we observed that the $\alpha$ FAP-S-PLO prodrug, lacking the MMP2 -sensitive linker peptide, but otherwise identical to $\alpha \mathrm{FAP}$ S-PL2, displayed almost no cytotoxic activity despite efficient binding to FAP-positive HT1080 cells (Figure 4c). Moreover, processing and cytotoxic activity of $\alpha \mathrm{FAP}-\mathrm{S}-\mathrm{PL} 2$ could be blocked by addition of the MMP inhibitor llomastat (Figure $4 a, d)$, suggesting that endogenous MMPs are responsible for prodrug activation. Together, these data provide strong evidence that antigen-specific recruitment to the cell surface of MMP-expressing cells is a prerequisite for efficient prodrug conversion and that processing is cleavage sequence specific. This mechanism ensures that restoration of TNF activity is locally restricted.

The phenomenon of membrane-restricted prodrug processing could be related to the activation mechanism of MMP-2. It is initially produced as a zymogen abundantly present in culture supernatants of HT1080 cells, while the active form of the enzyme can be barely detected. ${ }^{29}$ Activation of MMP-2 takes place on the cell surface in a complex multi-step process involving interaction with membrane-type matrix metalloproteinase 1 (MT1-MMP) and its physiological inhibitor TIMP-2, and intermolecular autocatalytic cleavage. ${ }^{22,31}$ Therefore, optimum cleavage of the TNF prodrug by the activated MMP-2 might only be achieved by appropriate localization on the cell surface, that is, upon prodrug binding to its target. The finding that pretreatment of the $\alpha \mathrm{FAP}-\mathrm{S}-\mathrm{PL} 2$ prodrug with recombinant MMP-2 did not result in further enhancement of cytotoxic activity on FAP-positive HT1080 cells indicated that the processing of the antigen-bound prodrug by endogenous MMPs was sufficient to reach maximum activation (Figure $4 \mathrm{e}$ ).

Antigen-negative HT1080 cells do not process the TNF prodrug and thus do not undergo apoptosis. Remarkably, when comparing TNF activity of in vitro preactivated $\alpha \mathrm{FAP}$. S-PL2 on FAP-positive versus -negative cells, it was striking that, although now cytotoxic activity of the activated TNF fusion protein could be discerned on FAP-negative cells, 
these cells were approx. 1000-fold less sensitive towards the active TNF fusion protein compared to FAP-positive cells (Figure 4e). Differences in the sensitivity towards TNF induced cell death between FAP-positive and -negative HT1080 cells could be ruled out, since not only soluble wild-type TNF but also preactivated $\alpha$ EDB-S-PL2 prodrug was comparably active on both cell lines $\left(E_{50}\right.$ of muTNF $\sim 0.5-1 \mathrm{pM} ; \mathrm{EC}_{50}$ of activated $\alpha$ EDB-S-PL2 $\sim 90 \mathrm{pM}$; data not shown). Thus, the enormous increase in TNF activity recovered from the $\alpha$ FAP-S-PL2 prodrug on FAP-positive HT1080 cells must be related to antigen-specific TNF fusion protein binding to the cell surface.

\section{The targeted, MMP-processed prodrug induces stable TNFR complexes and signals cell death towards target antigen-positive and -negative cells in a juxtatropic mode}

The observed enhancement of cytotoxicity of a targeted, activated prodrug could be due to appropriate presentation of the target antigen-bound, processed prodrug that enhances the probability of receptor clustering, a prerequisite likely for several, if not all, members of the TNFR family, and clearly relevant for signal transduction of both TNFR types. ${ }^{32,33} \mathrm{~A}$ high target antigen density may favor this presumed process of membrane assembly of a signal competent TNF ligand. Further, provided that the enhanced signal capacity is an intrinsic property of the membrane-assembled, activated prodrug, it follows that it should also signal in a juxtatropic mode and with equal efficiency towards TNFRs expressed on target-positive and -negative (bystander) cells. Indeed, coculture of FAP-positive and control HT1080 cells at various ratios induce overproportional cell death in the cultures upon prodrug treatment, clearly indicating bystander killing (Figure 5a). To resolve whether or not target antigen binding of the activated prodrug affects initial events in TNFR signal transduction and to formally prove juxtatropic action, we treated mixed cultures of FAP-positive and -negative cells with the TNF prodrug or an active derivative thereof, and studied the formation of TNFR clusters in target-negative HT1080 cells adjacent to target-positive HT1080 cells by confocal fluorescence microscopy (Figure 5b,c). For this purpose, target-negative cells were transiently transfected with a TNFR2-yellow fluorescent protein (YFP) fusion protein, because overexpression of TNFR1 and selection of stable transfectants is not possible, likely due to constitutive activation of TNFR1 and apoptosis induction. In order to visualize prodrug-binding cells, target-positive cells were transiently transfected with a cyan fluorescent protein (CFP) encoding vector.

The data obtained revealed TNFR2 cluster formation only in those cells that made close contacts to FAP-positive cells when incubated with a TNF fusion protein resembling the processed, active prodrug (Figure 5b, left panel), or upon preincubation with the TNF prodrug to allow processing on site (Figure 5b, right panel). A quantitative evaluation of TNFR2 cluster formation revealed that, under the conditions analysed ( $1 \mathrm{~h}$ treatment), approximately $50 \%$ of the TNFR2expressing cells in contact with a CFP-positive, that is, potentially prodrug binding, cell showed clear cluster formation at the contact site (Table 2). By contrast, in cocultures of TNFR2-expressing, target-negative, but MMP2-expressing HT1080 cells with target-negative HT1080 cells, TNFR2 cluster formation at incidental contact sites was not observed (Figure 5c, Table 2, <2\%). Basically, the same data were obtained using TNFR2-YFP-expressing Hela cells as target antigen-negative bystanders (data not shown). Formation of stable receptor complexes is a prerequisite for recruitment of signal adaptors conveying the activation downstream signal processes. ${ }^{32-34}$ For TNFR2, a receptor proximal event is the recruitment of TNF receptor-associated factor 2 (TRAF2). ${ }^{35}$ To further assess the formation of cytosolic receptor signal complexes, we used HT1080 cells stably expressing nonfluorescent TNFR2 and analyzed TRAF2 recruitment.

Ligation of TNFRs in stable TNFR2-overexpressing transfectants by juxtatropically presented activated prodrug caused translocation of a transiently expressed YFP-TRAF2 fusion protein from the cytosol to the plasma membrane at contact sites with prodrug-presenting cells (Figure $5 \mathrm{~d}, \mathrm{f}$ ), whereas YFP-TRAF2 distribution remained unchanged in the absence of FAP antigen (Figure $5 \mathrm{e}$ ). These data are formal proof that the target membrane-bound, processed prodrug is an efficient activator of TNFR2.

It has been shown that activation of TNFR2 can enhance TNFR1-mediated cytotoxicity. ${ }^{36,37}$ However, TNFR2 expression could not be detected on HT1080 cells (FAP antigen positive or negative) either by immunofluorescence flow cytometry (data not shown) or by IL-8 production after receptor stimulation (Figure 6a). Moreover, data from the HT1080-TNFR2 transfectants showed that, even when TNFR2 was overexpressed, coactivation of TNFR2 resulted in no or only little enhancement of TNFR1-mediated cytotoxicity (Figure 6b). Therefore, unlike in Colo205 or Kym-1 cells, ${ }^{36,37}$ in HT1080 cells, the enhanced cytotoxicity of the target membrane-bound, processed $\alpha$ FAP-S-PL2 cannot be explained by an enhancement of the TNFR1 apoptosis signalling via TNFR2 activation.

As overexpression of TNFR1 per se provokes ligandindependent clustering and signalling of cell death (own unpublished data), targeted ligand-induced receptor clustering cannot be visualized in this case. Nevertheless, it appears reasonable to assume that, as shown for TNFR2 (this study) and Fas, ${ }^{32,34}$ target antigen-dependent presentation of the processed prodrug likely induces stable complex formation of TNFR1, too, thereby enhancing apoptotic signal capacity.

Accordingly, the data show juxtatropic action of the processed prodrug and support our hypothesis that the enhanced activity of the targeted TNF prodrug correlates with its capability to mimick membrane TNF activity. This strikingly different bioactivity of this particular FAP-specific, processed TNF prodrug under targeted and nontargeted conditions could be an apparent advantage in terms of the achievable therapeutic window and safety for potential clinical applications. Even in the case of a systemic availability of a proportion of this prodrug in its active form, which may occur due to formation of an equilibrium between bound and unbound, processed prodrug, the in vitro data indicate that its TNF 

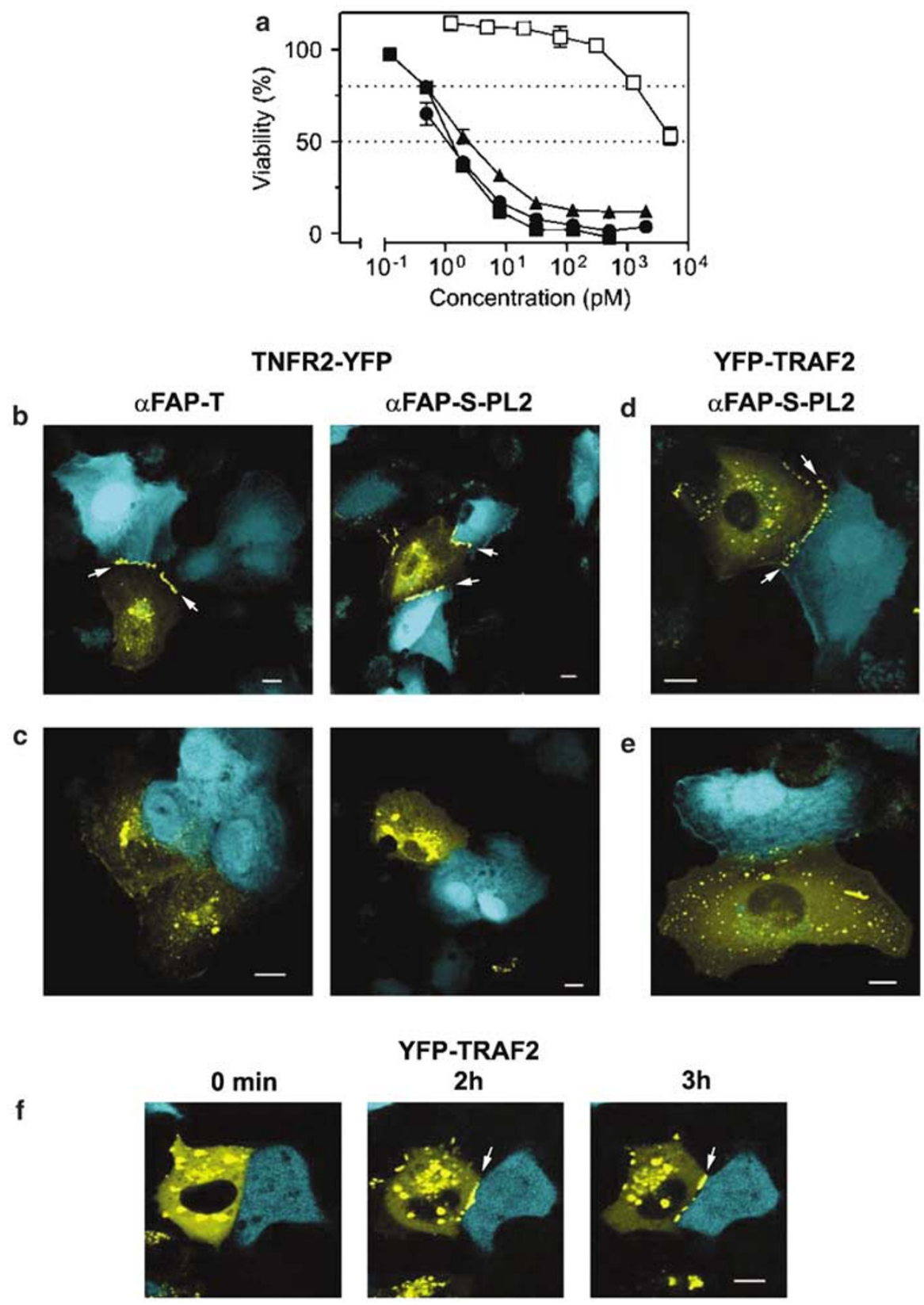

Figure 5 Juxtatropic action of TNF prodrug. (a) Cytotoxic effect of cell-surface-presented $\alpha$ FAP-S-PL2 towards antigen-negative bystander cells. At 1 day before incubating with TNF prodrug $\alpha$ FAP-S-PL2, HT1080-FAP and parental HT1080 cells were seeded either separately ( $:$ : HT1080-FAP; $\square:$ HT1080) or mixed ( $: 50 \%$ HT1080-FAP; $\mathbf{\Delta}: 20 \%$ HT1080-FAP). The next day, cell viability was determined by crystal violet staining. (b, c) TNFR2 cluster formation induced by antigen-presented aFAP-S-PL2 prodrug. CFP-expressing HT1080-FAP (b) or antigen-negative HT1080 (c) cells were cocultured with TNFR2-YFP-expressing HT1080 cells. Incubation with bioactive FAP-specific TNF fusion protein (left panel) or $\alpha$ FAP-S-PL2 prodrug (right panel)-induced antigen-dependent receptor clustering at membrane sites of juxtaposed cells $(\rightarrow)$. (d, e) aFAP-S-PL2 prodrug induces antigen-dependent TNFR2 activation evident from TRAF2 membrane translocation. CFP-expressing HT1080-FAP (d) or antigen-negative HT1080 (e) cells were cocultured with YFP-TRAF2-expressing HT1080-TNFR2 cells. TRAF2 translocation from the cytosol to plasma membrane at the contact sites with neighboring cells was only observed in cocultures with FAP antigen-expressing cells presenting prodrug ( $\rightarrow$ ). (f) Live imaging of TRAF2 membrane translocation after prodrug stimulation. A CFP-expressing HT1080-FAP cell and a YFP-TRAF2-expressing HT1080-TNFR2 cell displaying close contact were selected and observed before (left panel) and during stimulation with $\alpha$ FAP-S-PL2 prodrug (middle and right panel). Note the concurrent reduction in cytosolic levels of soluble TRAF2 in the cell, showing TRAF2 membrane translocation to the juxtaposed site. Scale bar shown is $10 \mu \mathrm{m}$

activity is inferior compared to standard TNF on nontargeted cells, whereas full activity requires antigen-directed cell surface presentation at the reactive stromal compartment of the tumor. As the latter is an abundant component of most solid tumors and a rich source of MMP-2, and because of potential juxtatropic action of a stroma-targeted cytokine, MMP-2-sensitive TNF prodrugs targeting ubiquitous and genetically stable markers such as FAP and ED-B appear to be a promising concept for treatment of MMP-overexpressing tumors. 
Table 2 Prodrug-mediated juxtatropic TNFR clustering and TRAF2 membrane translocation depends on binding to target cells

\begin{tabular}{llcr}
\hline & & & Cell 1 \\
\cline { 3 - 4 } & Cell 2 & HT1080, TNFR2-YFP & HT1080-TNFR2, YFP-TRAF2 \\
\hline$\alpha$ FAP-S-PL2 & HT1080-FAP, CFP & $51.5 \%$ & $64.6 \%$ \\
HFAP-T $^{\mathrm{a}}$ & HT1080, CFP & $1.9 \%$ & $2.0 \%$ \\
& HT1080-FAP, CFP & $39.7 \%$ & n.a. \\
& HT1080, CFP & $0 \%$ & n.a.
\end{tabular}

Relative numbers were revealed by counting contact-site-specific receptor clustering/TRAF2 translocation in relation to the total number of contact sites between a CFP and a YFP fusion protein positive cell. In all, 100-270 contact sites were analyzed after $1 \mathrm{~h}$ incubation with FAP-specific fusion protein. ${ }^{\mathrm{a}} \alpha \mathrm{FAP}-\mathrm{T}$ is a bioactive TNF fusion protein. ${ }^{\mathrm{b}}$ Not analysed
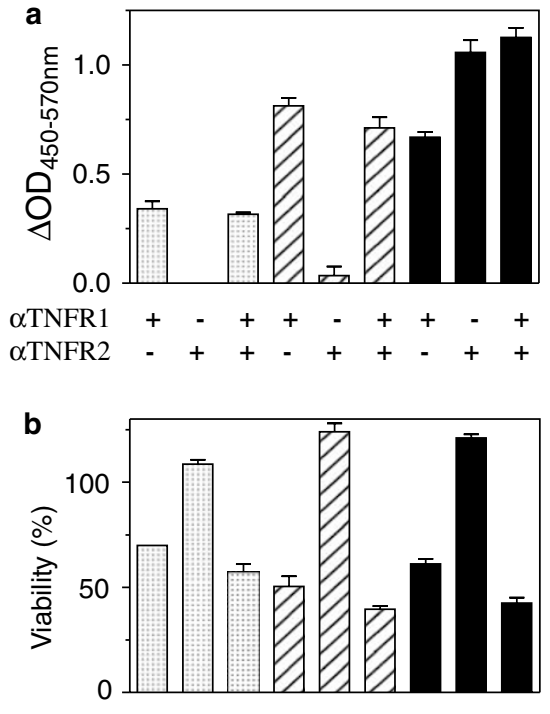

$\alpha \mathrm{TNFR} 1+-++\quad+\quad+\quad+$ $\alpha$ TNFR2 - ++-+++

Figure 6 Enhanced cytotoxicity of antigen-targeted, activated TNF prodrug is independent of TNF-R2. (a) TNF-R2 signaling is not detectable on HT1080/ HT1080-FAP cells. HT1080 (open bars), HT1080-FAP (hatched bars) and HT1080-TNFR2 (filled bars) were stimulated for $6 \mathrm{~h}$ with $\alpha$ TNFR1 and/or $\alpha$ TNFR2 antibodies $(31 \mathrm{ng} / \mathrm{ml})$ crosslinked with amouse Fc-specific antibodies $(2 \mu \mathrm{g} / \mathrm{ml})$, and receptor activation was analyzed by means of IL-8 production in ELISA. (b) TNF-R1-mediated cytotoxicity is not enhanced by TNF-R2 activation on antigen-positive or -negative HT1080 cells. HT1080 (open bars), HT1080FAP (hatched bars) and HT1080-TNFR2 (filled bars) were stimulated for $16 \mathrm{~h}$ with TNFR-specific antibodies $(18.5 \mathrm{ng} / \mathrm{ml})$ as described in (a). The following day, cytotoxicity was determined by measuring cell viability by crystal violet staining

\section{Materials and Methods}

\section{Cloning of the prodrug constructs}

The human scFv L19, specific for fibronectin ED-B, ${ }^{38}$ was amplified with a leader sequence from pIRES-AP39 (Schering AG) by proofreading PCR, introducing an EcoRI (forward primer) and an EcoRV (reverse primer) restriction site for insertion in the corresponding site of pcDNA3.1 (Invitrogen, Karlsruhe, Germany). The serin-glycin linker ( $\operatorname{Ser}_{4} \mathrm{Gly}_{3}$ was synthesized as two complementary oligos and introduced by EcoRV and Notl into pcDNA3.1 containing the L19 scFv. In parallel, the tenascin linker (chicken tenascin AA: $110-139$ ) was amplified by PCR from pW $32^{18}$ and incorporated into pcDNA3.1 containing the L19 scFv also using EcoRV/ Notl. The TNF module (deletion mutant of soluble murine TNF, $\triangle$ AA 1-9,
$\mathrm{K} 11 \mathrm{E})^{39}$ was added as PCR fragment (incorporation of Notl on the $\mathrm{N}$-terminal and Stul, Fsel, Acclll, EcoRI and Xbal on the C-terminal end by primer design) by Notl and Xbal. In case of the tenascin linker construct, the TNF module was amplified together with part of the proform of murine TNF (AA: -23 to -1 ) following the structural model of our previously published human TNF prodrug. ${ }^{18}$ In the next step, the scFv-TNF fusion constructs together with the leader sequence were cloned into the vector pIRES-DHFR (provided by Schering AG) via EcoRI. Next, the TNF inhibitory module represented by the human TNFR1 fragment (12-138AA), followed by a c-myc- and a His-tag, was introduced Cterminally to TNF by Fsel and Acclll after PCR amplification from pW32. ${ }^{18}$ Finally, the protease-sensitive linker consisting of three repeats of a MMP-2 motif separated by three glycines was introduced via Stul/Fsel in the form of two pairs of complementary oligos encoding the following protein sequence, PL1: GGGGPLG^VRGKGGGGPLG^VRGKGGGGPLG^VRGK; ${ }^{27}$ PL2: GGGHPVG^LLARGGGHPVG^LLARGGGHPVG^LLAR. ${ }^{26}$ These final prodrug constructs were designated as $\alpha$ EDB-S-PL1 and $\alpha$ EDB-S-PL2 for ED-B-specific TNF prodrugs comprising a serine-glycine linker between ScFv and TNF and MMP-sensitive linkers 1 and 2, respectively, between TNF and TNFR fragments. Similar constructs in which the serine-glycine linker was replaced by a tenascin linker were $\alpha$ EDB-T-PL1 and $\alpha$ EDB-T-PL2. To generate the FAP-specific prodrug $\alpha$ FAP-S-PL2, scFv L19 was replaced by the FAP-specific ScFv $36^{40}$ in the pIRES-DHFR construct containing the full prodrug $\alpha$ EDB-S-PL2 via EcoRV. Before, scFv 36 was amplified by PCR, introducing an EcoRV and an EcoRI site on the $5^{\prime}$ end and another EcoRV on the $3^{\prime}$ end. The prodrug constructs were cloned with the leader into the vector pCEP4 (Invitrogen, Karlsruhe, Germany) or pIRESpuro3 (BD Biosciences Clontech, Heidelberg, Germany) via EcoRI. For the FAP-specific control prodrug, $\alpha$ FAP-S-PL0 exchange of L19 was carried out in the corresponding pIRES-DHFR construct before the linker lacking MMP-2 cleavage motifs was inserted via Stul/Fsel (PLO: $\left.\left(\mathrm{S}_{4} \mathrm{G}\right)_{6}\right)$ as described for the MMP-2 site containing linkers. Finally, the $\alpha$ FAP-S-PLO construct was transferred into the pIRESpuro3 vector (BD Biosciences Clontech, Heidelberg, Germany). As positive controls, FAP-specific bioactive TNF fusion proteins comprising the scFv 36 and murine TNF either linked via serine glycine ( $\alpha$ FAP-S) or tenascin domain linker $(\alpha \mathrm{FAP}-\mathrm{T})$ were designed in analogy to the constructs described above. Restriction enzymes were purchased from New England Biolabs and MBI Fermentas.

\section{Production and purification of the prodrug}

Fusion proteins were produced in HEK293-EBNA cells by transient expression using Fugene (Roche, Mannheim, Germany) to introduce the expression plasmid pCEP-4 in the cells. After 2-3 days of cell culture in serum-free media, Optimem (Invitrogen, Karlsruhe, Germany) supernatants were harvested, dialyzed, and the fusion protein purified by 
immobilized metalchelate chromatography (IMAC) on $\mathrm{Zn}^{2+}$-loaded Hi-Trap columns (Amersham Biosciences, Freiburg, Germany) ( $\alpha$ FAPS-PL2; $\alpha$ FAP-S-PL0, $\alpha$ EDB-T-PL1), or by Protein-A affinity chromatography (Amersham Biosciences, Freiburg, Germany) ( $\alpha$ EDB-S-PL2). After dialysis against PBS, protein concentration was determined by the BCA method (Uptima, Interchim, France) and purification grade analysed by SDS-PAGE and silver staining (Sigma, Munich, Germany). Alternatively, the construct $\alpha$ FAP-S-PL0 or $\alpha$ FAP-S-PL2 in pIRESpuro3 was transfected with Lipofectamine 2000 (Invitrogen, Karlsruhe, Germany) in $\mathrm{CHO}$ or HEK293 cells, respectively, and stable transfectants were selected with puromycin. These cells were seeded and cultured with Optimem for 2-3 days. Supernatant was collected and proceded as described above.

\section{Cell lines}

The fibrosarcoma cell lines HT1080 and HT1080-FAP have been described previously, ${ }^{28,30}$ and were a kind gift of $W$ Rettig (Boehringer Ingelheim Pharma, Vienna, Austria). HT1080-TNFR2 cells were generated by transfection with TNFR2 in PCDM8 vector and stable clones selected with $600 \mu \mathrm{g} / \mathrm{ml} \mathrm{G} 418$, followed by repeated FACS. HEK293-EBNA cells were provided by Schering AG. The TNF-sensitive human rhabdomyosarcoma cell line KYM-1 was originally supplied by M Sekiguchi (University of Tokyo, Japan). CHO cells were obtained from ATCC. Cells were cultured in RPMI 1640 medium (Biochrom, Berlin, Germany) supplemented with $5 \%$ fetal calf serum. HT1080-FAP cells were grown in the presence of $250 \mu \mathrm{g} / \mathrm{ml} \mathrm{G} 418$. Stable transfectants of $\alpha$ FAPS-PLO-expressing $\mathrm{CHO}$ cells were cultivated in the presence of $10 \mu \mathrm{g} / \mathrm{ml}$ puromycin and HEK293 stably expressing $\alpha$ FAP-S-PL2 were cultivated with $2 \mu \mathrm{g} / \mathrm{ml}$ puromycin.

\section{Western blot analysis}

Purified proteins or supernatants were separated on a $12 \%$ SDS-PAGE under reducing conditions and electroblotted to nitrocellulose membrane (Schleicher \& Schuell, Deisenhofen, Düsseldorf). Nonspecific binding was blocked with $2 \%$ Tween 80 and detection performed with rabbit antimurine TNF- $\alpha$ Ab (HyCult Biotechnology, PB Uden, The Netherlands) and alkaline phosphatase-conjugated goat anti-rabbit IgG Ab (Sigma, Munich, Germany) or $9 \mathrm{E} 10$ (anti-c-myc) mouse $\mathrm{mAb}$ and alkaline phosphataseconjugated goat anti-mouse IgG Ab (Sigma, Munich, Germany) using nitro blue tetrazolium and 5-bromo-4-chloro-3-indolyl phosphate (Roth, Karlsruhe, Germany) as substrates.

\section{Size exclusion chromatography}

Analysis of the apparent molecular weight of $\alpha$ FAP-S-PL2 was performed by size exclusion chromatography on a Superdex ${ }^{\mathrm{TM}} 200$ (Amersham Biosciences, Freiburg, Germany) column under standard conditions with a flow rate of $0.5 \mathrm{ml} / \mathrm{min}$ and $\mathrm{PBS}$ as running buffer.

\section{Immunofluorescence flow cytometry}

HT1080 and HT1080-FAP cells were incubated for $2 \mathrm{~h}$ at $4^{\circ} \mathrm{C}$ with $10 \mu \mathrm{g} / \mathrm{ml}$ of $\alpha$ FAP-S-PL2, $\alpha$ FAP-S-PL0 or $\alpha$ EDB-S-PL2. Bound prodrug was detected by anti-c-myc $9 \mathrm{E} 10 \mathrm{mAb}$, followed by fluoresceine isothiocyanate-labeled rabbit anti-mouse IgG Ab (Sigma, Munich, Germany). Analyses were performed using EPICS-XL (Coulter, Krefeld, Germany) according to standard procedures.

\section{ELISA}

96-well-plates were coated overnight at $4^{\circ} \mathrm{C}$ with $130 \mathrm{ng} /$ well of recombinant ED-B (provided by Schering $A G$ ). After blocking with 3\% (w/v) dry milk in PBS containing $0.05 \%$ Tween 20 , the prodrug (activated/ not activated) was titrated in duplicates. Detection was performed with horseradish peroxidase-conjugated Protein A (Sigma, Munich, Germany), using TMB substrate reagent set (BD Biosciences, Heidelberg, Germany) and stopping the reaction with $1 \mathrm{M} \mathrm{H}_{2} \mathrm{SO}_{4}$.

\section{In vitro activation of the TNF prodrug}

The optimized reaction conditions for complete proteolytic activation of the TNF prodrugs were the following: $12 \mu \mathrm{g} / \mathrm{ml}$ of purified prodrug was incubated with $2 \mu \mathrm{g} / \mathrm{ml}$ recombinant MMP-2 (Merck Biosciences $\mathrm{GmbH}$, Schwalbach, Germany) in reaction buffer ( $50 \mathrm{mM}$ Tris, $20 \mu \mathrm{M} \mathrm{ZnSO}$, $1 \mathrm{mM} \mathrm{CaCl}_{2}, 0.05 \%$ Brij 35, pH 7.5) for $4-6 \mathrm{~h}$ at $37^{\circ} \mathrm{C}$. MMP-2 inhibition was assayed by preincubation for $15 \mathrm{~min}$. with $2.5 \mu \mathrm{g} / \mathrm{ml}$ MMP Inhibitor III (Merck Biosciences GmbH, Schwalbach, Germany). For prodrug activation in an antigen-bound state, an ELISA plate was coated with recombinant ED-B ( $230 \mathrm{ng} /$ well) overnight at $4^{\circ} \mathrm{C}$. The following day, the plate was blocked with $10 \%$ fetal calf serum in phosphate-buffered saline (PBS), followed by incubation with $1 \mu \mathrm{g} / \mathrm{ml}$ prodrug for $1.5 \mathrm{~h}$ at RT. After washing three times with PBS, the plate was incubated for $6 \mathrm{~h}$ at $37^{\circ} \mathrm{C}$ with $1 \mu \mathrm{g} / \mathrm{ml}$ recombinant MMP-2 in reaction buffer (50 mM Tris, $20 \mu \mathrm{M} \mathrm{ZnSO}_{4}$, $1 \mathrm{mM} \mathrm{CaCl}_{2}, 0.05 \%$ Brij 35, pH 7.5). The plate was washed again and $2 \times 10^{4} \mathrm{Kym}-1$ cells/well seeded to directly reveal the presence of activated prodrug in a bioassay (induction of cell death) as described below.

\section{Cytotoxicity assays}

Kym- 1 cells $\left(1.5 \times 10^{4} /\right.$ well) were grown overnight in $100 \mu$ l of culture medium in 96-well plates. The following day, prodrug (activated or not) was titrated at the indicated concentrations on the cells in duplicates. After overnight incubation, cell viability was determined using 3-[4,5-dimethylthiazol-2-yl]-2,5-diphenyltetrazolium bromide (MTT) staining as described previously. ${ }^{18}$ OD values of untreated control cells have been set as $100 \%$ viability. For analyses of activation of antigen-bound prodrug (see above), Kym-1 cells were added directly to the pretreated wells and analysed for cell viability $16 \mathrm{~h}$ later. For the cytotoxicity assay on HT1080 or HT1080FAP cells, $2 \times 10^{4}$ cells/well were seeded and purified prodrugs or supernatants titrated in the presence of $2.5 \mu \mathrm{g} / \mathrm{ml}$ cycloheximide. After overnight incubation, cell viability was assessed by crystal violet staining as described. ${ }^{30}$ Binding competition was assayed by incubating the cells for $1 \mathrm{~h}$ with $13 \mu \mathrm{g} / \mathrm{ml}$ of the recombinant Ab MB36 prior to the addition of the prodrug. For endogenous MMP-2 inhibition, cells were preincubated with $25 \mu \mathrm{M}$ llomastat (Chemicon International, Hofheim, Germany). Cytotoxicity of FAP-specific prodrug towards cocultured FAP-expressing and parental HT1080 cells was carried out similarly by seeding mixtures of these cells in the indicated proportions. For Ab-mediated cytotoxicity, HT1080, HT1080-FAP or HT1080-TNFR2 cells $\left(2 \times 10^{4} /\right.$ well) were incubated with $18.5 \mathrm{ng} / \mathrm{ml}$ of $\mathrm{H} 398$ (mouse anti-TNFR1, own production) and/or MR2-1 (mouse anti-TNFR2, HyCult Biotechnology, Uden, The Netherlands). After $0.5-1 \mathrm{~h}, 2 \mu \mathrm{g} / \mathrm{ml}$ goat anti-mouse IgG, Fc-specific (Jackson Immuno Research, Cambridgeshire, UK), was added for crosslinking receptor specific antibodies and cell viability assessed after overnight incubation. 


\section{Analysis of prodrug fusion proteins after incubation on HT1080 or HT1080-FAP cells}

HT1080 or HT1080-FAP cells $\left(2 \times 10^{4} /\right.$ well) were grown overnight in $100 \mu \mathrm{l}$ culture medium in 96-well plates. The following day, the medium was replaced by $100 \mu$ l Optimem with $20 \mathrm{nM}$ purified prodrug ( $\alpha$ FAPS-PL2, $\alpha$ EDB-S-PL2, $\alpha$ FAP-S-PL0) or supernatant ( $\alpha$ FAP-S). After $16 \mathrm{~h}$ incubation, the supernatant was harvested, centrifuged and further analyzed by Western Blot and cytotoxicity assay on HT1080 cells as described above.

\section{IL-8 ELISA}

For analysis of IL-8 production after receptor activation, HT1080, HT1080FAP or HT1080-TNFR2 cells $\left(1 \times 10^{4} /\right.$ well) were grown overnight in $100 \mu \mathrm{l}$ culture medium in 96-well plates. The following day, the medium was replaced by culture medium containing $31 \mathrm{ng} / \mathrm{ml}$ of $\mathrm{H} 398$ (mouse anti-TNFR1, own production) and/or MR2-1 (mouse anti-TNFR2, HyCult Biotechnology, Uden, The Netherlands). After $30 \mathrm{~min}, 2 \mu \mathrm{g} / \mathrm{ml}$ goat anti-mouse IgG, Fc-specific (Jackson Immuno Research, Cambridgeshire, UK), was added for crosslinking receptor specific antibodies. After $6 \mathrm{~h}$ incubation, supernatants were harvested, centrifuged and analyzed by IL-8 ELISA kit (BD Biosciences, Heidelberg, Germany) according to the manufacturer's instructions.

\section{Microscopic analysis}

For transient expression of CFP, TNFR2-YFP or TRAF2-YFP, $5 \times 10^{6}$ FAP-expressing, TNFR2-expressing or parental HT1080 cells were transfected by electroporation ( $250 \mathrm{~V}, 1800 \mu \mathrm{F}$, EasyJecT Plus, Peqlab, Erlangen, Germany) with $10 \mu \mathrm{g}$ of the respective DNA plasmids (pECFP$\mathrm{C} 1$, TRAF2 in pEYFP-C1 and TNFR2 in pEYFP-N1; original vectors were obtained by BD Biosciences Clontech, Heidelberg, Germany). In order to evaluate TNFR2 cluster formation or TRAF2 translocation, $1 \times 10^{5}$ YFP fusion protein-transfected cells were cocultured with $1 \times 10^{5}$ of CFPtransfected cells, either directly after transfection or 1 day later, in Sterilin plates containing $18 \times 18 \mathrm{~mm}^{2}$ glass coverslips. After overnight incubation, cocultures were stimulated with $0.5 \mu \mathrm{g} / \mathrm{ml} \alpha \mathrm{FAP}-\mathrm{S}-\mathrm{PL} 2$ or positive control (a FAP-specific bioactive TNF fusion protein) for $30 \mathrm{~min}, 1$ or $2.5 \mathrm{~h}$, followed by fixation with $3.5 \%$ paraformaldehyde for $10 \mathrm{~min}$ at $37^{\circ} \mathrm{C}$. Glass coverslips with fixed cells were inverted and mounted on slides with Fluoromount-G (Southern Biotech, Birmingham, AL, USA). Cells were imaged with a Leica TCS SP2 confocal laser scanning microscope (LSM) on a DM RE microscope stand using Leica LCS software. Images were acquired with a HCX PL Apo $\times 40 / 1.25$ UV objective lens. CFP was excited with a $454 \mathrm{~nm}$ line of an argon laser and fluorescence was detected from 465 to $500 \mathrm{~nm}$. YFP was excited with a $514 \mathrm{~nm}$ line and fluorescence was detected from 535 to $600 \mathrm{~nm}$. Images were acquired sequentially to minimize crosstalk of fluorescence emission. Quantitative analysis was performed by counting the positive events (receptor clustering or TRAF2 membrane translocation at contact sites) out of 100-270 total events (contact site between a CFP and a YFP fusion protein-expressing cell).

For live cell imaging, cocultures of CFP- and TRAF2-expressing cells were seeded in $35 \mathrm{~mm}$ glass-bottom culture dishes (MatTek Corporation, Ashland, MA, USA; $5 \times 10^{5}$ cells, respectively). Cell pairs of FAP-positive, CFP-transfected and parental HT1080 cells, TRAF2-YFP-transfected, were observed before and after stimulation with $\alpha$ FAP-S-PL2 at the indicated time points. Experiments were carried out on a Leica TCS SL LSM (on an inverted DM-IRBE microscope stand equipped with a $\mathrm{CO}_{2}$ - incubation chamber and a peltier element block for temperature control (Pecon, Germany)). Images were acquired with a HCX PL Apo CS $\times 63 /$ 1.32 UV objective lens. CFP-transfected cells were imaged with the $454 \mathrm{~nm}$ laser line and fluorescence was detected from 465 to $500 \mathrm{~nm}$. TRAF2-YFP cells were imaged with the $514 \mathrm{~nm}$ laser line and fluorescence was detected from 550 to $650 \mathrm{~nm}$. Both channels were also acquired sequentially to minimize crosstalk between CFP and YFP fluorescence.

Microscope systems and Leica LCS software were from Leica Microsystems $\mathrm{GmbH}$, Mannheim, Germany. Images were filtered with a Median filter (radius 1 pixel) to reduce noise, and levels and contrast were adjusted automatically with Photoshop software (Adobe, USA).

\section{Acknowledgements}

This work was supported by grants from Wilhelm Sander-Stiftung, grant no. 2003.120.1, Deutsche Krebshilfe, grant no. 10-1751 and Schering AG.

\section{References}

1. Eggermont AM and ten Hagen TL (2001) Isolated limb perfusion for extremity soft-tissue sarcomas, in-transit metastases, and other unresectable tumors: credits, debits, and future perspectives. Curr. Oncol. Rep. 3: 359-367

2. Mueller $H$ (1998) Tumor necrosis factor as an antineoplastic agent: pitfalls and promises. Cell. Mol. Life Sci. 54: 1291-1298

3. Corti A (2004) Strategies for improving the anti-neoplastic activity of TNF by tumor targeting. Methods Mol. Med. 98: 247-264

4. Borsi L, Balza E, Carnemolla B, Sassi F, Castellani P, Berndt A, Kosmehl H, Biro A, Siri A, Orecchia P, Grassi J, Neri D and Zardi L (2003) Selective targeted delivery of TNFalpha to tumor blood vessels. Blood 102: 4384-4392

5. Bauer S, Adrian N, Williamson B, Panousis C, Fadle N, Smerd J Fettah I, Scott AM, Pfreundschuh M and Renner C (2004) Targeted bioactivity of membraneanchored TNF by an antibody-derived TNF fusion protein. J. Immunol. 172: 3930-3939

6. Kuroda K, Miyata K, Fujita F, Koike M, Fujita M, Nomura M, Nakagawa S, Tsutsumi $Y$, Kawagoe T, Mitsuishi $Y$ and Mayumi T (2000) Human tumor necrosis factor-alpha mutant RGD-V29 (F4614) shows potent antitumor activity and reduced toxicity against human tumor xenografted nude mice. Cancer Lett. 159: 33-41

7. Curnis F, Sacchi A, Borgna L, Magni F, Gasparri A and Corti A (2000) Enhancement of tumor necrosis factor alpha antitumor immunotherapeutic properties by targeted delivery to aminopeptidase N (CD13). Nat. Biotechnol. 18: $1185-1190$

8. Curnis F, Sacchi A and Corti A (2002) Improving chemotherapeutic drug penetration in tumors by vascular targeting and barrier alteration. J. Clin. Invest. 110: $475-482$

9. Curnis F, Gasparri A, Sacchi A, Longhi R and Corti A (2004) Coupling tumor necrosis factor-alpha with alphaV integrin ligands improves its antineoplastic activity. Cancer Res. 64: 565-571

10. Lu F, Chen ZM, Liu QH and Chen CQ (2001) A novel human tumor necrosis factor alpha mutant showed potent antitumor activity and reduced toxicity in vivo. Acta Pharmacol. Sin. 22: 619-623

11. Cha SS, Kim JS, Cho HS, Shin NK, Jeong W, Shin HC, Kim YJ, Hahn JH and Oh BH (1998) High resolution crystal structure of a human tumor necrosis factor-alpha mutant with low systemic toxicity. J. Biol. Chem. 273: 2153-2160

12. Yoshioka $Y$, Tsutsumi $Y$, Ikemizu S, Yamamoto $Y$, Shibata H, Nishibata $T$ Mukai Y, Okamoto T, Taniai M, Kawamura M, Abe Y, Nakagawa S, Nagata S, Yamagata Y and Mayumi T (2004) Optimal site-specific PEGylation of mutant TNF-alpha improves its antitumor potency. Biochem. Biophys. Res. Commun. 315: 808-814

13. Yamamoto $Y$, Tsutsumi $Y$, Yoshioka $Y$, Nishibata T, Kobayashi K, Okamoto T, Mukai Y, Shimizu T, Nakagawa S, Nagata S and Mayumi T (2003) Site-specific PEGylation of a lysine-deficient TNF-alpha with full bioactivity. Nat. Biotechnol. 21: $546-552$ 
14. Kamada $\mathrm{H}$, Tsutsumi $\mathrm{Y}$, Yamamoto $\mathrm{Y}$, Kihira $\mathrm{T}$, Kaneda $\mathrm{Y}, \mathrm{Mu} \mathrm{Y}$, Kodaira $\mathrm{H}$, Tsunoda SI, Nakagawa S and Mayumi T (2000) Antitumor activity of tumor necrosis factor-alpha conjugated with polyvinylpyrrolidone on solid tumors in mice. Cancer Res. 60: 6416-6420

15. Murdter TE, Friedel G, Backman JT, McClellan M, Schick M, Gerken M, Bosslet K, Fritz P, Toomes H, Kroemer HK and Sperker B (2002) Dose optimization of a doxorubicin prodrug (HMR 1826) in isolated perfused human lungs: low tumor $\mathrm{pH}$ promotes prodrug activation by beta-glucuronidase. J. Pharmacol. Exp. Ther. 301: 223-228

16. Pan C, Cardarelli PM, Nieder MH, Pickford LB, Gangwar S, King DJ, Yarranton GT, Buckman D, Roscoe W, Zhou F, Salles A, Chen TH, Horgan K, Wang YH, Nguyen T and Bebbington CR (2003) CD10 is a key enzyme involved in the activation of tumor-activated peptide prodrug $\mathrm{CPI}-0004 \mathrm{Na}$ and novel analogues: implications for the design of novel peptide prodrugs for the therapy of CD10+ tumors. Cancer Res. 63: 5526-5531

17. DeFeo-Jones D, Garsky VM, Wong BK, Feng DM, Bolyar T, Haskell K, Kiefer DM, Leander K, McAvoy E, Lumma P, Wai J, Senderak ET, Motzel SL, Keenan K, Van Zwieten M, Lin JH, Freidinger R, Huff J, Oliff A and Jones RE (2000) A peptide-doxorubicin 'prodrug' activated by prostate-specific antigen selectively kills prostate tumor cells positive for prostate-specific antigen in vivo. Nat. Med. 6: $1248-1252$

18. Wuest T, Gerlach E, Banerjee D, Gerspach J, Moosmayer D and Pfizenmaier K (2002) TNF-Selectokine: a novel prodrug generated for tumor targeting and site-specific activation of tumor necrosis factor. Oncogene 21: 4257-4265

19. Garin-Chesa P, Old LJ and Rettig WJ (1990) Cell surface glycoprotein of reactive stromal fibroblasts as a potential antibody target in human epithelial cancers. Proc. Natl. Acad. Sci. USA 87: 7235-7239

20. Castellani P, Viale G, Dorcaratto A, Nicolo G, Kaczmarek J, Querze G and Zardi $L$ (1994) The fibronectin isoform containing the ED-B oncofetal domain: a marker of angiogenesis. Int. J. Cancer. 59: 612-618

21. Kaczmarek J, Castellani P, Nicolo G, Spina B, Allemanni G and Zardi L (1994) Distribution of oncofetal fibronectin isoforms in normal, hyperplastic and neoplastic human breast tissues. Int. J. Cancer. 59: 11-16

22. Hofmann UB, Westphal JR, van Muijen GN and Ruiter DJ (2000) Matrix metalloproteinases in human melanoma. J. Invest. Dermatol. 115: 337-344

23. Duffy MJ, Maguire TM, Hill A, McDermott E and O'Higgins N (2000) Metalloproteinases: role in breast carcinogenesis, invasion and metastasis. Breast Cancer Res. 2: 252-257

24. Liabakk NB, Talbot I, Smith RA, Wilkinson K and Balkwill F (1996) Matrix metalloprotease 2 (MMP-2) and matrix metalloprotease 9 (MMP-9) type IV collagenases in colorectal cancer. Cancer Res. 56: 190-196

25. Heppner KJ, Matrisian LM, Jensen RA and Rodgers WH (1996) Expression of most matrix metalloproteinase family members in breast cancer represents a tumor-induced host response. Am. J. Pathol. 149: 273-282

26. Turk BE, Huang LL, Piro ET and Cantley LC (2001) Determination of protease cleavage site motifs using mixture-based oriented peptide libraries. Nat. Biotechnol. 19: 661-667

27. Bremer $\mathrm{C}$, Tung $\mathrm{CH}$ and Weissleder $\mathrm{R}$ (2001) In vivo molecular target assessment of matrix metalloproteinase inhibition. Nat. Med. 7: 743-748
28. Samel D, Muller D, Gerspach J, Assohou-Luty C, Sass G, Tiegs G, Pfizenmaier $\mathrm{K}$ and Wajant $\mathrm{H}$ (2003) Generation of a FasL-based proapoptotic fusion protein devoid of systemic toxicity due to cell-surface antigen-restricted Activation. J. Biol. Chem. 278: 32077-32082

29. Stanton H, Gavrilovic J, Atkinson SJ, d'Ortho MP, Yamada KM, Zardi L and Murphy G (1998) The activation of ProMMP-2 (gelatinase A) by HT1080 fibrosarcoma cells is promoted by culture on a fibronectin substrate and is concomitant with an increase in processing of MT1-MMP (MMP-14) to a $45 \mathrm{kDa}$ form. J. Cell Sci. 111: 2789-2798

30. Wajant H, Moosmayer D, Wuest T, Bartke T, Gerlach E, Schonherr U, Peters $\mathrm{N}$, Scheurich P and Pfizenmaier K (2001) Differential activation of TRAIL-R1 and -2 by soluble and membrane TRAIL allows selective surface antigendirected activation of TRAIL-R2 by a soluble TRAIL derivative. Oncogene 20: $4101-4106$

31. Will H, Atkinson SJ, Butler GS, Smith B and Murphy G (1996) The soluble catalytic domain of membrane type 1 matrix metalloproteinase cleaves the propeptide of progelatinase $A$ and initiates autoproteolytic activation. Regulation by TIMP-2 and TIMP-3. J. Biol. Chem. 271: 17119-17123

32. Algeciras-Schimnich A, Shen L, Barnhart BC, Murmann AE, Burkhardt JK and Peter ME (2002) Molecular ordering of the initial signaling events of CD95. Mol. Cell. Biol. 22: 207-220

33. Krippner-Heidenreich A, Tubing F, Bryde S, Willi S, Zimmermann G and Scheurich $P(2002)$ Control of receptor-induced signaling complex formation by the kinetics of ligand/receptor interaction. J. Biol. Chem. 277: 44155-44163

34. Henkler F, Behrle E, Denney KM, Wiskovsky A, Peters N, Warnke C, Pfizenmaier $\mathrm{K}$ and Wajant $\mathrm{H}$ (2005) The extracellular domains of FasL and Fas are sufficient for the formation of supramolecular FasL-Fas clusters of high stability. J. Cell Biol. 168: 1087-1098

35. Wajant $H$, Pfizenmaier $K$ and Scheurich $P$ (2003) Tumor necrosis factor signaling. Cell Death Differ. 10: 45-65

36. Grell M, Douni E, Wajant H, Lohden M, Clauss M, Maxeiner B, Georgopoulos S, Lesslauer W, Kollias G, Pfizenmaier K and Scheurich P (1995) The transmembrane form of tumor necrosis factor is the prime activating ligand of the $80 \mathrm{kDa}$ tumor necrosis factor receptor. Cell 83: 793-802

37. Grell M, Zimmermann G, Gottfried E, Chen CM, Grunwald U, Huang DC, Wu Lee $\mathrm{YH}$, Durkop H, Engelmann H, Scheurich P, Wajant $\mathrm{H}$ and Strasser A (1999) Induction of cell death by tumour necrosis factor (TNF) receptor 2, CD40 and CD30: a role for TNF-R1 activation by endogenous membrane-anchored TNF. EMBO J. 18: 3034-3043

38. Pini A, Viti F, Santucci A, Carnemolla B, Zardi L, Neri P and Neri D (1998) Design and use of a phage display library. Human antibodies with subnanomolar affinity against a marker of angiogenesis eluted from a twodimensional gel. J. Biol. Chem. 273: 21769-21776

39. Willuweit A, Sass G, Schoneberg A, Eisel U, Tiegs G and Clauss M (2001) Chronic inflammation and protection from acute hepatitis in transgenic mice expressing TNF in endothelial cells. J. Immunol. 167: 3944-3952

40. Brocks B, Garin-Chesa P, Behrle E, Park JE, Rettig WJ, Pfizenmaier K and Moosmayer D (2001) Species-crossreactive scFv against the tumor stroma marker 'fibroblast activation protein' selected by phage display from an immunized FAP-/- knock-out mouse. Mol. Med. 7: 461-469

Supplementary information accompanies the paper on Cell Death and Differentiation website (http://www.nature.com/cdd) 